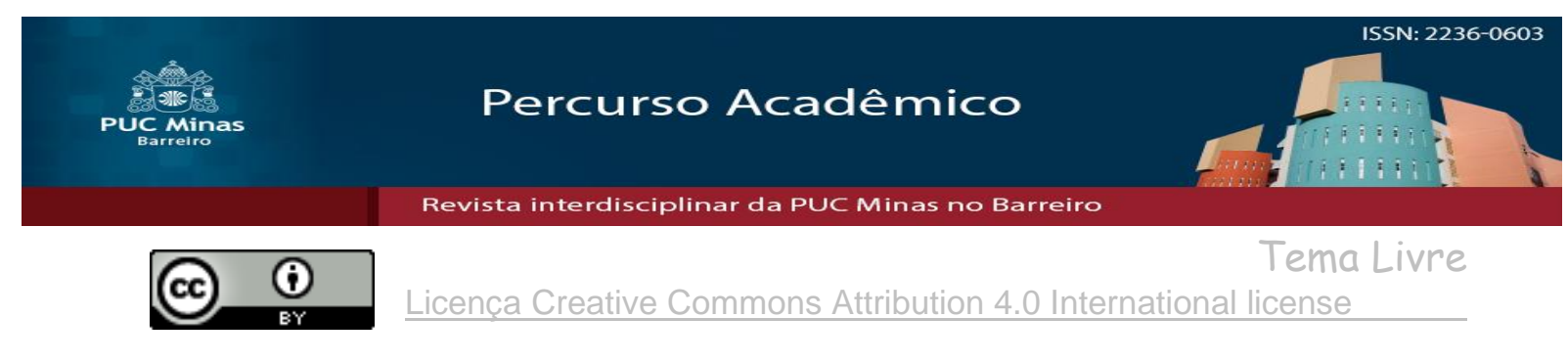

\title{
A antijuridicidade do benefício fiscal judicial
}

\author{
The illegality of the judicial tax benefit
}

William Chaves Souza ${ }^{1}$

\begin{abstract}
RESUMO
Este artigo trata da impossibilidade de criação/ampliação de benefício fiscal regularmente instituído em lei por decisão judicial assentada em alguma técnica de integração ou no exercício da prerrogativa hermenêutica. Faz uso de racionalizações derivadas da Análise Econômica do Direito, máxime das conclusões acerca: (i) da consagração da representatividade democrática, das preferências sociais e da segurança jurídica no direito fundamental à legalidade, e especificamente na legalidade tributária; e (ii) da eficiência adjudicatória - a partir dos parâmetro Kaldor-Hicks -, e da investigação do espaço criativo legado aos juízes, tomando por base tanto o esquema integrativo do Código Tributário Nacional - para as lacunas da lei isentiva -, quanto a tese da "hermenêutica das escolhas" - para os casos de ambiguidade e obscuridade da lei instituidora de benefício tributário. Ilustra a prodigalidade do Judiciário em matéria de ampliação de benefícios fiscais a partir de casos julgados no Supremo Tribunal Federal e conclui pela ineficiência e inadequação da decisão judicial ampliativa/criativa de favorecimento tributário, ante o dever de interpretação literal, a impossibilidade lógica de lacuna na lei isentiva decorrente da sua condição alternativa de regulação de fato de interesse tributário; e, nos casos de ambiguidade da lei, da necessária interpretação restritiva das situações de exceção, em razão da primazia da indisponibilidade do patrimônio público.
\end{abstract}

Palavras-chave: Benefício fiscal. Poder Judiciário. Eficiência. Análise Econômica do Direito. Ativismo Judicial.

\begin{abstract}
This article deals with the impossibility of creating/extending a tax benefit regularly established in law by judicial decision based on some integration technique or the exercise of hermeneutic prerogative. It makes use of rationalizations derived from the Law and Economics field, mainly the conclusions about: (i) the consecration of democratic representativeness, social preferences and legal security by the fundamental right to legality, and specifically in tax legality; and (ii) adjudicatory efficiency - based on the Kaldor-Hicks parameter -, and from the investigation of the creative space granted to judges, based on both the integrative scheme of the National Tax Code - for the gaps in the exemption law -, and the thesis of the "hermeneutics of choices" - for cases of ambiguity and obscurity in the law establishing tax benefit. It illustrates the prodigality of the Judiciary in terms of expanding tax benefits from cases judged by the Supremo Tribunal Federal and concludes for the inefficiency and inadequacy of the extending/creative judicial decision of tax favoring, given the duty of literal interpretation, the logical impossibility of a gap in exemption law arising from its alternative condition of tax interest facts regulation; and, in cases of ambiguity in the law, the necessary restrictive interpretation of exceptional situations, due to the primacy of the unavailability of public assets.
\end{abstract}

Keywords: Tax benefit. Judiciary Branch. Efficiency. Law and Economics. Judicial activism.

\footnotetext{
Artigo recebido em 26 de setembro de 2021 e aprovado em 23 de novembro de 2021.

${ }^{1}$ Mestrando em Direito do Centro Universitário de Brasília, pós-graduado em Direito Tributário pela Universidade Candido Mendes e graduado em Direito pela Universidade Federal de Goiás. Atua profissionalmente como Auditor Fiscal da Receita Federal do Brasil. E-mail: william.souza.chaves@gmail.com
} 


\section{INTRODUÇÃO}

O artigo trata da impossibilidade de ampliação de benefícios físcais pelo Poder Judiciário. O problema é sumarizado da seguinte forma: na configuração de Estado de Direito, o Poder Judiciário tem base jurídica geral que estribe decisão que cria/amplia benefício fiscal, pelas vias integrativa ou interpretativa?

A hipótese explorada é a de que, mesmo nos casos em que há lacuna ou obscuridade da fórmula legal, a decisão ampliativa não se adequa à estrutura do Sistema Tributário Nacional: é inconstitucional e alocativamente ineficiente.

Os juízes são agentes estatais vocacionados à solução pacífica de controvérsias por enforcement das regras jurídicas; função imprescindível à estabilidade social. Necessário, portanto, ter instrumentos de controle da atuação afastada das diretivas legais. Isso torna extremamente importante investigar os limites decisórios desses agentes.

O que se pretende é uma leitura acerca da adequação jurídica das decisões judiciais que, sob pretexto interpretativo, realizam a ampliação de benefícios fiscais. Alerta-se que, a despeito de haver escólio diferenciando benefícios e incentivos fiscais, aqui o uso da expressão "benefícios fiscais" abrange qualquer situação de favorecimento tributário legal (isenções, anistias, diferimentos etc.), ou mesmo imunidades - preservadas as suas particularidades.

Parte-se de pressupostos rígidos que envolvem as searas tributária e financeira, como a mandatória observação da reserva legal, a segurança jurídica e a sustentabilidade orçamentária; e com o uso de ferramental da Análise Econômica do Direito, investiga-se o espaço de liberdade decisória que há para o agente adjudicador, em face dos vetores estruturantes do Estado democrático de Direito.

$\mathrm{O}$ artigo inicia com exemplos de tutela ativista ampliativa, depois explora os conceitos de legalidade e eficiência, sob a ótica da revelação de preferências sociais, a partir da qual se extrai a conexão que há entre eles. Adiante, traz análise das balizas normativas que envolvem o tema; revela as restrições lógicas e interpretativas oponíveis ao julgador; e assinala a mácula da solução extensiva à separação dos poderes. Ademais, explora-se a ideia de sustentabilidade financeiro-orçamentária.

Por fim, fita-se o processo de colmatação de lacunas legais pelas técnicas de integração e como essas técnicas se relacionam com legalidade e preferências sociais; e a gradação de liberdade hermenêutica nos contextos de anomia e ambiguidade da norma. Essa discussão 
permite pôr em perspectiva a atuação do judiciário ante o dever de eficiência em face de pleito ampliativo de benefício fiscal.

\section{PRODIGALIDADE JUDICIÁRIA EM MATÉRIA DE BENEFÍCIOS FISCAIS}

A despeito de toda a discussão acerca dos limites da legitimidade democrática da jurisdição ativista (BARROSO, 2009, p. 6), há temas cuja discussão não comporta a persecução da justiça para além dos limites legais. Um desses é a criação/ampliação de benefícios fiscais.

As disposições constitucionais e legais que circundam a matéria são todas restritivas e só dão espaço aos juízes para que façam controle limitado, apenas quanto ao cumprimento das formalidades rituais da instituição legal. A reserva legal, a indisponibilidade do patrimônio público e os deveres de interpretação literal e eficiência se combinam em uma inescapável conclusão: não há espaço ao judiciário para a criação ou ampliação de benefício de natureza tributária.

Entretanto, o que se vê em várias decisões judiciais não poderia estar mais distante dessa conclusão. Um claro exemplo de avanço sobre esses limites é o caso em que se discutiu, no Supremo Tribunal Federal, se a amplitude da imunidade objetiva sobre o papel destinado à impressão de livros seria extensível aos suportes de livros eletrônicos. A despeito de apreciar a solução ampliativa conferida ao caso, pelas premissas aqui apresentadas, ela é equivocada.

Vários outros julgados da própria Corte, em que o trato imune é negado para os mais diversos insumos utilizados na produção de "livros, jornais e periódicos", que aderem à norma constitucional de modo mais efetivo, confirmam essa afirmação. Há uma grande seletividade na escolha de critérios decisórios e alto teor de substituição do Poder Legislativo, a quem caberia redefinir a amplitude da dita imunidade. $\mathrm{O}$ argumento central da redefinição é de prisma teleológico, mas o argumento analógico é a via de acesso à conclusão.

Noutro caso em que a Corte avança sobre a independência do Poder Legislativo, assumiu que há omissão legislativa e expandiu o universo de beneficiários da isenção de IPI na aquisição de automóveis, instituída pela Lei ${ }^{\circ}$ 8.989, de 24 de fevereiro de 1995 . Na decisão proferida no julgamento da Ação Direta de Inconstitucionalidade por Omissão (ADO) $n^{\circ}$ 30/DF, o acórdão (BRASIL, 2020, p. 2) argumenta que a não inclusão dos deficientes auditivos no escopo da lei é instituição de política pública incompleta, 
portanto passível de ter reconhecida a omissão parcial. Em razão de a lei não ter trazido trato específico para esse tipo de deficiência, por raciocínio analógico, aplicou o art. $1^{\circ}$, IV, da lei aos acometidos com tal condição e ordenou ao congresso Nacional que expeça lei regulando o caso em 180 dias.

Veja-se que o alargamento se deu de forma irrestrita, sem parâmetros e justificado por um senso de equidade particular dos julgadores, sem qualquer cuidado com impactos outros senão o de inclusão dos deficientes auditivos na política pública mencionada. Presumiu-se que houve omissão por parte do legislador, quando na realidade a exclusão desse tipo específico de deficiente decorre da liberdade legiferante de seleção de beneficiários ao instituir a política tributária favorecida.

Mais uma vez, não se discorda do resultado, mas da forma equivocada de atingi-lo. Uma coisa é haver omissão real, outra é a fabricação de omissão por via argumentativa. A determinação de regulação é clara forma de inibir que os colegiados legisladores façam escolhas diversas do que o Tribunal considera adequado, o que evidencia um descompasso inter-poderes, que revela um problema de agência; e a substituição do legislativo instituindo política tributária isentiva sob o argumento de omissão é o produto desse problema.

A mesma isenção tem aspecto interessante que pode contribuir para a compreensão da linha que se defende neste texto: o caput do artigo $1^{\circ}$ da Lei $\mathrm{n}^{\circ} 8.989$, de 1995 , limita o objeto sobre o qual recai a isenção a "automóveis de passageiros de fabricação nacional". A limitação do benefício a produto nacional defronta acordos e convenções internacionais firmados, em que se pactua igualdade de tratamento quanto aos tributos internos para o produto importado - e.g. importações originárias de países-membros do Mercosul, (art. $7^{\circ}$ do Tratado Mercosul - promulgado pelo Decreto $n^{\circ} 350$ de 1991). Logo, a ampliação interpretativa do objeto é decorrência dos referidos acordos, não da expansão de significado do enunciado em qualquer dimensão.

Para finalizar com exemplos, vale mencionar a criação, pelo STF, de novo benefício de IPI na Zona Franca de Manaus (ZFM). Na prática, não ampliou um benefício fiscal que ali existe, mas criou um até então inexistente por via hermenêutica que contradiz a tese assentada no Enunciado da Súmula Vinculante (SV) no 58 da Corte: "Inexiste Direito a crédito presumido de IPI relativamente à entrada de insumos isentos, sujeitos à alíquota zero ou não tributáveis, o que não contraria o princípio da não cumulatividade.”

O cerne era a interpretação da regra de não cumulatividade do imposto, acerca da qual há farta literatura e jurisprudência chancelando a impossibilidade do que se firmou, mas em 
uma construção esotérica desconectada de qualquer senso de consequências e baseada em sofismas, como a especialidade da Zona Franca. A propósito de interpretação de norma obscura, o Tribunal agiu de modo oportunista e criou regra jurídica casuística anômala.

Casos assim mostram o quanto o Judiciário tem de se imiscuir na atividade legislativa positiva, ou pressupor defeito normativo inexistente, para sustentar decisão ampliativa de benefícios. Em ambas as situações, não há falta de clareza e não há lacuna. Como se verá adiante, são decisões ineficientes, se não inconstitucionais, tendo em vista que a decisão deveria convergir para o que é semanticamente congruente com o texto legal/constitucional, em respeito à estrutura interpretativa restritiva imposta à autoridade judicante, derivada da conformação dada pelo Sistema Tributário Nacional.

\section{LEGALIDADE: UMA MEDIDA DA EFICIÊNCIA DOS JUÍZES}

A Análise Econômica do Direito (AED) oferece instrumental eficiente para a compreensão do Direito de um prisma funcional, como tecnologia social de modulação comportamental (COOTER; ULEN, 2011, p.3). Percebe a construção jurídica como uma matriz intrincada de incentivos que influenciam na tomada de decisão pelos sujeitos destinatários (POSNER, 1975, p. 761). Portanto, trabalha com a ideia de modelagem comportamental atomizada dos agentes econômicos para chegar a modelos comportamentais elaborados e derivar conclusões acerca do comportamento agregado; ao que se denomina individualismo metodológico (MISES, 1998, p. 44-47).

Quanto mais complexas e numerosas se tornaram as sociedades, mais ferramentas de harmonização se mostraram necessárias. Isso em mente, duas coisas saltam em evidência: (i) a necessidade de criação de fórmulas de estabilização social, ou seja, de prover as pessoas com formulações de conduta que sejam justas, para que concordem com elas e haja a adesão voluntária a tais formulações - criação de leis; e (ii) a necessidade de correção da conduta desviada, como forma de coibir a extração de utilidade da não adesão à regra pelo agente desviado - enforcement.

O Direito é calcado na necessidade de estabilidade e previsibilidade que aumenta nas pessoas o senso de segurança. Extrai-se tanta utilidade desses elementos que as sociedades contemporâneas têm se valido de construções similares e dedicado vultosas somas de recursos a título de tributos, deveres e obrigações (custo social do Estado) em favor da manutenção da macroestrutura idealizada para a consecução desse propósito por agentes especializados (GICO JR, 2020, p. 59-62). 
Portanto, em um Estado de Direito estribado na democracia, as preferências sociais serão reveladas pelos agentes políticos eleitos, em um jogo permanente de defesa de interesses, que as exterioriza através da lei, e de concessões a configurações normativas por ela permitidas. A lei, portanto, é o instrumento concebido para estratificar as preferências agregadas.

Além disso, é anseio de qualquer indivíduo minimamente racional que a atuação de todo e qualquer agente estatal se dê com eficiência. Tanto é assim que a Constituição Federal de $1988(\mathrm{CF} / 88)$, reconhecendo isso, dispõe tal parâmetro como princípio geral da Administração Pública ( $\mathrm{CF} / 88$, art. 37) e o invoca repetidamente em vários contextos. Em linhas gerais, o dito princípio é comando que submete a ação estatal ao dever de eficiência; e isso redunda inclusive na lei processual: art. $8^{\circ}$ do Novo Código de Processo Civil (NCPC), Lei $\mathrm{n}^{\circ} 13.105$, de 16 de março de 2015. O comando implica o juiz no dever de mirar a eficiência, tanto na condução processual (visando eficiência produtiva) quanto na aplicação do Direito material (visando eficiência alocativa).

No contexto, o dever de eficiência se dá em duas dimensões: (i) produtiva, que basicamente se relaciona com o custo da prestação jurisdicional, em que fica claro o dever de aumento de produtividade (fazer mais com os mesmos recursos), ou o de economicidade (fazer o mesmo com menos recursos); (ii) alocativa, pela qual se evidencia a preocupação com o retorno ou a utilidade extraída da prestação jurisdicional, e isso implica análise de adequação da escolha realizada (decisão) - assim, há eficiência alocativa quando a decisão realiza a melhor alocação dos recursos levando em conta as preferências da sociedade (GICO JR, 2020, p.57), ou seja, maximize o bem-estar social segundo tais preferências.

Portanto, tendo em conta que a grande questão do presente trabalho é a pertinência de um tipo específico de alocação (de ativo tributário em litígio), cabe sumarizar o critério de eficiência de Kaldor-Hicks - o critério deriva da junção das proposições dos economistas Nicholas Kaldor e John Richard Hicks, em dois papers que se complementam em ideias (KALDOR, 1939; HICKS, 1939). O interesse nesse critério se dá, pois possibilita apontar algo objetivo acerca da mudança de estados sociais em que há partes prejudicadas e outras beneficiadas, como é o caso da atividade judicante.

Segundo o critério Kaldor-Hicks de eficiência, uma mudança de estado social será considerada eficiente (aumentará o bem estar-social) apenas se (i) após a implementação, os beneficiários de determinada política pública possam compensar os prejudicados e, ainda assim, tenham benefício líquido positivo (critério de Kaldor); e, (ii) no momento 
pré-implementação, os possíveis prejudicados não tenham capacidade de compensar os potenciais agraciados para que estes renunciem aos benefícios da mudança, sem que fiquem em pior situação do que ficariam se a mudança ocorresse (critério de Hicks).

$\mathrm{Na}$ matriz da atividade adjudicatória, alguém é beneficiado (vencedor) e alguém é prejudicado (sucumbente). Desse modo, ao conjecturar a aplicação do critério de eficiência exposto a tal atividade, percebe-se que é necessário ter um referencial estável que direcione quais as preferências sociais a serem perseguidas, pois a aproximação desse referencial denota esforço de incremento do bem-estar coletivo. Portanto, tendo em conta que à lei cabe agregar e referenciar tais preferências, quanto mais aderente à regra jurídica, mais a decisão judicial tende a ser Kaldor-Hicks eficiente.

Assim, como o Direito predefinido pelo legislador é o referencial mais próximo possível das preferências da sociedade, se o juiz adjudica o bem a quem determina o Direito, sua decisão será alocativamente eficiente. "Em outras palavras, o princípio da eficiência processual no seu aspecto alocativo é satisfeito quando o juiz aplica a lei, 'pois ela já representa o julgamento de valor da sociedade sobre o estado da natureza que prefere'." (GICO JR., 2020, p. 63).

\section{ESQUADRO LEGAL DA AMPLIAÇÃO DE BENEFÍCIOS FISCAIS}

A pergunta que se propõe neste item é a seguinte: se o Poder Legislativo - que pode criar - está limitado, há justificativa no ordenamento para que o Poder Judiciário não adira às regras jurídicas que lhe impõem limitações?

Essencialmente, o Direito tem sido uma tecnologia social de legitimação do monopólio da força e da estruturação do poder do Estado; o primeiro se traduz no poder de coerção, e visa enforcement e o propósito de modular a conduta desviada para a direção estabelecida pelas regras; o que revela que a efetividade dos parâmetros vertidos nas fontes do Direito só tem sentido se há formas de fazer valerem as regras. Isso se dá, em última instância, pelo exercício da jurisdição e seus mecanismos de constrangimento ("legítimos") aceitos pela sociedade.

Sabe-se que em um Estado democrático deve predominar a vontade da maioria; portanto, a revelação das preferências sociais se dá através dos produtos da política, prioritariamente pelas normas regularmente produzidas pelos representantes eleitos. Como já dito, nesse contexto, a lei é o instrumento primordial de revelação das preferências de uma sociedade organizada em um Estado. 
O nicho tributário é parcela especializada do Direito cujo mister é o financiamento da ação estatal na busca de soluções para a realização das prioridades eleitas pela sociedade, mirando o bem-estar social, mormente através das funções da tributação: incremento de receita, redistribuição de renda e correção de externalidades (KAPLOW, 2007). Por representar violência estatal contra a propriedade do particular, tributar é atividade estritamente vinculada à lei.

Portanto, grosso modo, porque há custos para tornar efetivos os Direitos eleitos como caros à sociedade (HOLMES \& SUNSTEIN, 1999; BRÄUTIGAM, 2002), ao Estado é legítima a violência patrimonial vinculada contra os indivíduos, a partir da constrição de numerário a título de tributo. O consenso político para tal, entretanto, estabelece inúmeras limitações aos entes estatais competentes a figurar no polo ativo da relação jurídicotributária. Dentre essas limitações, há de se ressaltar a ordem de vinculação à legalidade. Constitucionalmente prevista nos art. $5^{\circ}$, II, e art. 150, I, condicionantes de juridicidade da instituição de exação tributária; e no art. $150, \S 6^{\circ}$, condicionante da instituição de causa exoneradora de tributo. Dada a indisponibilidade do patrimônio público, a autorização de qualquer ato que gere impacto sobre a exigibilidade do crédito tributário somente pode ser feita por lei específica, sem prejuízo da exigibilidade de prévio convênio entre estados, quando tratar-se do ICMS.

O Código Tributário Nacional (CTN), Lei n 5.172, de 1966, em seu art. $3^{\circ}$ define tributo como "prestação pecuniária compulsória (...) instituída em lei...”, e o art. 97 enumera os elementos da norma de incidência que não podem ser definidos senão em diploma legal. O inciso VI desse artigo informa que são matérias de exclusividade da lei as hipóteses de exclusão (isenção e anistia), suspensão e extinção do crédito tributário, além das de dispensa ou redução de penalidades. Aliado a isso, o mesmo CTN define a necessária literalidade interpretativa da norma isentiva (art. 111): formulação que reflete a legalidade para dentro do núcleo da liberdade decisória do julgador, limitando-a.

Os limites impositivos à atividade tributário-coercitiva materializam, portanto, modo de proteção dos agentes em suas individualidades patrimoniais. Razão por que no Sistema Tributário Nacional inaugura-se estrutura jurídico-positiva que dá tipologia cerrada à norma tributária, cujos elementos devem obrigatoriamente ser definidos em lei estrita, pois só assim a configuração de incidência de tributo será legítima, segundo nossa arquitetura.

O mesmo pode ser dito quando se trata de retirar o ônus tributário que recai sobre alguém.

Se a norma de incidência onera o particular, a norma de não incidência assimétrica - que 
discrimina particulares beneficiários -, onera o grupo, uma vez que encerra iniciativa redistributiva. Logo, em último caso, implica ônus ao particular não beneficiado. Assim, também a iniciativa de exoneração deve ser vinculada à estrita medida posta em lei, sob o risco de se admitir ao Estado a violência patrimonial casuística, imprevisível e oportunista, postura que erode a autoridade estatal (ARRUDA, 2019, p.2) e promove insegurança jurídica.

A ampliação de benefício fiscal é, de fato, um ato de criação. Não é outra a razão de as normas tratarem os dois casos de modo equivalente. Ora, ampliar, é novar em algum aspecto: sujeito favorecido, quantum devido (base de cálculo e alíquota), ou extensão temporal. Por essa linha, é fácil perceber que a ampliação significa instituição de novo ônus, possivelmente não estimado na instituição originária, portanto requer reavaliação de adequação de custos e capacidade de concessão pelo ente titular do tributo.

Deve-se manter em mente que instituição e ampliação de benefício fiscal são envolvidas por duas perspectivas: (i) uma estritamente jurídica, que pretende estabelecer uma estrutura de proteção ao direito de arrecadar (ou melhor, o poder-dever de arrecadar, ante a plena vinculação da atividade fiscal arrecadatória), que grava várias condicionantes a serem observadas para que a instituição ou majoração de benefício seja juridicamente válida; e (ii) uma pragmática, econômica, pois é um claro caso de política pública calcada na perseguição de objetivo extrafiscal, i.e., traduz esforço intervencionista estatal (que abre mão do direito de invasão patrimonial que tem, na busca de um objetivo qualquer alheio à arrecadação). Logo, qualquer que seja a razão, é lógico, do ponto de vista da eficiência da disposição de recursos públicos, que o favorecimento seja vinculado a uma contrapartida que se traduza em utilidade social no mínimo equivalente ao montante que se deixa de recolher.

Na Constituição Federal de 1988 (CF/88), o art. 150, § $6^{\circ}$ é a regra que baliza a questão. Institui a obrigatoriedade de lei específica para a concessão de subsídio ou isenção, redução de base de cálculo, concessão de crédito presumido, anistia ou remissão, relativos a impostos, taxas ou contribuições. A regra não apresenta qualquer obscuridade, e, na defesa do interesse público, reclama, inclusive, interpretação ampliativa, na direção de condicionar à legalidade estrita toda e qualquer forma de concessão de vantagem fiscal (como diferimento e crédito financeiro proporcional a tributo etc.).

Destaca-se, portanto, que a par de se exigir lei para a instituição dos tributos, a Constituição estabelece, em seu art. 150, $\S 6^{\circ}$, que a concessão de benefícios fiscais também depende de lei específica, "que regule exclusivamente a matéria ou o 
correspondente tributo, sem prejuízo de se exigir, para benefícios de ICMS, ainda, prévio convênio entre os Estados (art. 155, § $2^{\circ}$, XII, g)" (PAULSEN, 2020, p. 188). E entre os benefícios enquadra-se qualquer subsídio ou isenção, redução de base de cálculo, concessão de crédito presumido, anistia ou remissão.

Sabe-se que a preocupação constitucional é a preservação do equilíbrio orçamentário, mas também visa combater o comportamento oportunista do legislador, que se manifesta principalmente na inserção de caudas legislativas em projetos cuja matéria se tenha consenso. Tamanha é a preocupação do ordenamento com a questão, que a Lei Complementar $\mathrm{n}^{\circ} 95$, de 26 de fevereiro de 1998, no art. $7^{\circ}$, II, revela que esse cuidado deve ser generalizado, nos seguintes termos: "a lei não conterá matéria estranha a seu objeto ou a este não vinculada por afinidade, pertinência ou conexão.” Tal comando, quando associado ao parágrafo único do art. $1^{\circ}$ da mesma Lei, permite compreender que mesmo as emendas parlamentares a projetos e medidas provisórias devem respeito a tal requisito formal de validade da lei.

Fora isso, a sustentabilidade orçamentária também impõe regras, como as dispostas no art. 14 da Lei de Responsabilidade Fiscal e no art. 113 do Ato das Disposições Constitucionais Transitórias (ADCT), que denotam a preocupação estatal com o oportunismo na criação ou ampliação desses benefícios. Isso posto, vale analisar os ditos esquadros normativos referentes à responsabilidade fiscal, a iniciar pelos requisitos do art. 14 da Lei de Responsabilidade Fiscal (LRF) - Lei complementar $n^{\circ} 101$, de 4 de maio de 2000 - que condicionam aspectos da proposição legislativa que carreia criação ou ampliação de benefício de natureza tributária. A norma exige do proponente a apresentação de estimativa de impacto orçamentário-financeiro, a demonstração de que a renúncia está computada na lei orçamentária e o apontamento de medidas compensatórias à renúncia de receitas estimada.

A escusa de atendimento às condições é um problema recorrente que grava as proposições de vício formal, uma vez que o texto legal verte os tais como requisitos estritos de juridicidade da proposição, cujo objetivo é possibilitar aos colegiados legislativos, na apreciação da medida, a tomada de decisão informada. Assim, a finalização do processo legislativo sem sua observação dá origem a norma que aumenta o passivo orçamentário. Note-se que a própria Comissão de Finanças e Tributação da Câmara dos Deputados tem enunciado sumulado relativo ao tema, em que sumariza a inadequação da proposição que não esteja acompanhada de estimativa de impacto financeiro-orçamentário e não indique 
a respectiva fonte de compensação (a Súmula $n^{\circ} 1 / 2008$, da Comissão de Finanças e Tributação).

Ressalte-se que essa diretriz foi reforçada em regra de estatura constitucional no art. 113, do Ato das Disposições Constitucionais Transitórias (ADCT), no bojo das redefinições financeiro-orçamentárias instituídas pela Emenda Constitucional n ${ }^{\circ}$ 95, de 2016, que instituiu o Novo Regime Fiscal - cujo mote é o equilíbrio das contas públicas. Além disso, o art. 109, § $2^{\circ}$, II, do ADCT, passou a prever o descumprimento do limite de gastos do Poder Executivo como causa de vedação à concessão ou ampliação de benefício de natureza tributária.

Voltando ao art. 37, da CF/88, cabe evidenciar que o legislador também é vinculado pelo dever de eficiência. Não tem, portanto, espaço para se afastar da imposição legal, e deve perseguir a produção eficiente da lei, e isso não ocorre se o próprio legislador se afasta das regras jurídicas que condicionam sua atuação.

Em suma, a necessária observação da reserva legal é limitação que se impõe tanto aos Poderes Executivo e Legislativo quanto ao Judiciário; e como evidenciado, as limitações formais à ampliação de incentivos fiscais dirigidas ao Poder Legislativo consistem na necessária observação da reserva legal: lei específica que observe as formalidades de rito e de preservação da sustentabilidade financeiro-orçamentária (estimativas de perda de receita e medidas compensatórias); e na vedação de emendas fora do escopo temático. Ante tal quadro soa necessário relativizar a situação da seguinte forma: se para o legislador há vários requisitos para ampliar benefícios, por que o magistrado estaria livre para fazê-lo a partir de expediente puramente hermenêutico?

Felizmente, a lei traz resposta à questão. Também destinada a inibir comportamento oportunista, mas dirigida ao aplicador da lei, a cláusula geral de interpretação aposta no art. 111 do Código Tributário ressoa a intenção de combate a esse tipo de atuação. Procura-se condicionar as possibilidades de leitura - máxime ao juiz, dito intérprete autêntico (GRAU, 2006, p. 89-90) - da lei tributária exoneradora, para que este não seja incutido em vício evidenciado pelo problema agente-principal no qual o juiz (agente) passa a decidir segundo sua conveniência, em vez de se ater aos limites do mandante Estado (principal).

A fórmula eleita pelo artigo denota-o corolário da indisponibilidade do patrimônio público (BALEEIRO; DERZI, 2018), uma vez que imprime diretriz interpretativa restritiva à lei que institua benefício tributário, radicado teleologicamente sobre a 
limitação da evasão de numerário dos cofres públicos para além do estritamente conexo à literalidade da regra jurídica, considerado seu limiar semântico.

$\mathrm{Na}$ medida em que o favorecimento de parcela da sociedade com um benefício fiscal representa (i) a ampliação de ônus aos não beneficiados; ou (ii) se dá em face do aumento da eficiência produtiva do Estado, que no mínimo estaria fazendo o mesmo com menos (atuando com economicidade), ou mais com menos - em face do incremento incessante das demandas sociais. Como essa segunda hipótese é improvável, há certo grau de certeza na afirmação de que a desoneração de um grupo representa oneração à sociedade em geral.

A despeito de a estrutura de condução processual ter outros meios recursais de correção do comportamento oblíquo do juiz, como a remessa necessária e o efeito devolutivo amplo da apelação, tenta-se, no indigitado dispositivo, conter o avanço da sombra do retro referido problema de agência, pela limitação da amplitude hermenêutica ao agente adjudicador: a leitura ampliativa é imediatamente rechaçada: a interpretação literal homenagem à segurança jurídica - reafirma a legalidade tributária em toda sua extensão (SABBAG, 2010, p. 641). Entretanto, mesmo em razão da obrigatoriedade de estribar a compreensão da norma na literalidade de significação, deve-se apontar que mesmo uma técnica notadamente oclusa de leitura não obriga à dissociação contextual do comando regulador, pois implicaria risco de construção de incoerência e irracionalidade da interpretação.

Assim, a leitura literal não exclui a necessidade de se considerarem: circunstâncias de aplicação, finalidade perseguida e adequação (coerência textual e contextual) (BALEEIRO; DERZI, 2018) da norma, mesmo que tenha de ser concluído em decodificação que não amplie ou reduza a extensão. Todavia, nenhum desses elementos tem substância autônoma que possibilite a transcendência do texto, apenas agregam à amálgama argumentativa que se imiscui na revelação do esquadro semântico do texto. Isso, porque a invocação normativa da interpretação literal pretende evitar que o intérprete amplie certos conceitos ou proponha leitura que adstringe a intenção do ente legislador. Como se vê, o Poder Legislativo, que é quem carrega o mandato social para privilegiar e revelar as preferências sociais, está cercado de condições para exercer sua atividade típica de legislar acerca da ampliação de benefício fiscal. Coerentemente, o Poder Judiciário recebe comandos claros limitantes de sua criatividade decisória: além dos requisitos formais ínsitos à sentença válida, a criação/ampliação de benefício tributário é matéria reservada à lei, a interpretação da lei que o faz deve ser literal, e se, em exercício 
integrativo oblíquo, decide segundo valoração abstrata, está vinculado ao dever de "consideração das consequências práticas da decisão".

É essa a prescrição do art. 20 da Lei de Introdução às Normas de Direito Brasileiro (LINDB) - Decreto-Lei no 4.657, de 4 de setembro de 1942: "Nas esferas administrativa, controladora e judicial, não se decidirá com base em valores jurídicos abstratos sem que sejam consideradas as consequências práticas da decisão.” Perceba-se que o juiz, quando amplia a regra exoneradora por via da interpretação, sequer opera real ampliação, pois cria favorecimento fiscal sem liame legal, i.e., na prática, substitui o legislador. Isso é crítico, principalmente em face dos impactos econômicos (orçamentários, concorrenciais, alteração da estrutura de incentivos etc.) e da subversão casuística da ordem jurídica (segurança jurídica, depreciação do valor informativo do Direito, imprevisibilidade etc.), razão por que, ao assumir ou se apresentar uma conjuntura em que tal possibilidade se mostre válida, deve ele, ainda, se pautar pela eficiência em face das consequências.

\section{A ANTIJURIDICIDADE DA DECISÃO AMPLIATIVA}

Nesta seção, analisa-se como o Poder Judiciário submetido ao cânone do non liquet é ativo na criação de normas, exercendo real função legislativa positiva. Isso é posto em paralelo às limitações formais e substantivas a serem enfrentadas na formulação de regra tributária ampliativa de regalia fiscal. A conclusão inescapável é de que apesar de o Poder Judiciário ter delegações pontuais para legislar, o juiz eficiente respeitará limitações lógicas e jurídicas no desempenho de sua função.

Conquanto a aplicação do Direito seja a função essencial de várias instituições especializadas integrantes do Poder Executivo, é no Judiciário que se revela a forma definitiva de aplicação, em face da cláusula constitucional de inafastabilidade da jurisdição (art. $5^{\circ}, \mathrm{XXXV}, \mathrm{CF} / 88$ ). Assim, como visto na seção precedente, defronte qualquer contingência, mesmo no contexto de civil law, em que se tenta centralizar a atividade legislativa no Poder Legislativo, ao Judiciário cabe o preenchimento residual de lacunas: a atuação não se limita, portanto, à imposição de regras, mas mesmo sua criação ou modificação (ARRUÑADA; ANDONOVA, 2005, p. 200) vestigiais.

Como foi dito, a eficiência alocativa da prestação jurisdicional tem amplitude relativa dependente da aderência à lei. Desse modo, a prestação jurisdicional despreocupada desse dever de eficiência traduz real problema de agência, pois as decisões praeter, ultra ou contra legem são extratos do oportunismo do julgador, logo tendem a ser ineficientes. 
O preceptivo do art. $5^{\circ}, \mathrm{XXXV}$, da $\mathrm{CF} / 88$ elege a jurisdição inafastável como esteio garantidor de direitos, que traduz a possibilidade de qualquer ameaça de lesão ser levada a juízo. Já o art. 140 do Código de Processo Civil (CPC) é claro ao vedar ao agente adjudicador que se exima de decidir, mesmo em face de anomia ou obscuridade da norma; é a conhecida vedação ao non liquet. Tal diretriz é acompanhada de prescrições outras que auxiliam o julgador na solução de casos em que há omissão ou vício de clareza do texto de norma (GICO JR, 2018).

Dado o escopo da discussão do presente artigo, exploram-se as ferramentas destinadas ao suprimento das lacunas, i.e., os métodos de integração e o espaço de escolhas hermenêuticas (GICO JR, 2020, p. 63). Vale dizer que o emprego de tais técnicas é mandatório, logo o juiz não tem total liberdade para decidir - e criar a regra que aplicará ao caso - como quiser.

A despeito de haver discussão da doutrina civilista contemporânea acerca da obrigatoriedade ou não da aplicação sequencial dos métodos integradores vertidos no art. $4^{\circ}$ da LINDB, em face da força normativa dos princípios gerais de Direito constitucionalizados, máxime os conexos à dignidade humana, este trabalho é estribado em uma compreensão clássica de integração. Ora, se a aplicação irrestrita de princípios passasse ser a regra, não restaria qualquer lacuna a preencher. Isso é ilógico, tendo em vista que o ordenamento reconhece que as lacunas existem, e propõe formas de as colmatar (GICO JR., 2018, p. 65).

Segundo a "estrutura analítica da integração" (GICO JR, 2020, p. 64) - e o art. 4, da LINDB -, no caso de omissão legal, o espaço decisório do juiz é limitado pela necessidade de emprego de expedientes integrativos que respeitam uma lógica de aplicação, pela qual se deve privilegiar, em ordem, as técnicas segundo a maior probabilidade de sua aproximação com as preferências sociais. Assim, a aplicação da analogia deve preceder a aplicação dos costumes e estes à decisão baseada nos princípios gerais do Direito.

Assim, se a lei é a melhor representação do agregado das preferências sociais, em face de uma fonte de Direito omissa (no caso da tributação, a lei) quanto a uma situação específica, não há revelação das preferências sociais quanto à matéria; entretanto, se há regra jurídica que trate de caso análogo, aproveitar essa regra ao caso leva a uma aproximação do que seriam tais preferências para a solução do problema. Assim, a solução analógica tende a ser alocativamente eficiente por privilegiar essa aproximação racional. 
Se não há regra jurídica passível de aplicação estendida ao caso, cabe ao julgador tentar identificar se há algum costume (prática social reiterada de forma generalizada e prolongada) de que se possa extrair uma regra de conduta com a qual se possa resolver o caso, e aplicá-la. A utilização do costume também aproxima a decisão das preferências sociais, logo também é eficiente. Não havendo, pois, lei análoga ou costume, o próximo passo que pode ser dado pelo julgador é decidir com base nos princípios gerais de Direito: terá grande margem de liberdade para construção da solução, e restará privilegiado seu próprio senso de justiça.

O contexto tributário, entretanto, tem várias particularidades que inviabilizam a plena aplicação da integração. A começar pelo art. 108, do CTN, que propõe que à analogia (I), segue-se a aplicação de princípios gerais de Direito tributário (II), que, mesmo sendo mais abstratos do que regras, condensam intimidade temática à matéria tributária, logo preferíveis aos seus subsequentes “princípios gerais de Direito público" (III) e "equidade" (IV). Percebe-se, portanto, que o Código Tributário exclui a possibilidade de utilização dos costumes do arsenal integrativo, mas traz a mesma lógica de afastamento gradual das preferências sociais e simultâneo aumento da liberdade criativa do juiz.

Como se viu, ante a omissão legal, a própria lei autoriza ao juiz que invente uma regra jurídica para solver o caso, e rotula isso como integração "para amenizar o fato de estarem efetivamente inventando a regra naquele momento. De qualquer forma, a regra inventada como subproduto da prestação do serviço público adjudicatório passará a integrar o ordenamento jurídico.” (GICO JR. 2018, p. 62).

Deve-se sobrelevar, contudo que, quando a matéria tratada é a instituição de favorecimento tributário, a necessária interpretação literal vincula à aplicação do método restritivo de leitura, motivo pelo qual "derrogam-se, na interpretação restritiva, os critérios de integração da norma, isto é, não se aplicam os meios integrativos às hipóteses previstas no art. 111 do CTN." (SABBAG, 2010, p. 641).

Outra coisa a manter em mente é que a lei instituidora de benesse fiscal tem dever de completude (cf. LC nº 95, de 1999, art. 11, cuja prescrição é: “As disposições normativas serão redigidas com clareza, precisão e ordem lógica, observadas, para esse propósito, as seguintes normas: ...”) e é cercada de condições. Sua fórmula, de modo análogo à da norma de incidência, deve abranger os sujeitos a que destinada, o tributo, as hipóteses de exclusão, o quantum, o período de vigência da exoneração, assim como delimitar o espaço geográfico de aplicação, se for o caso. De forma ideal, trata-se de norma que seria plenamente dotada de clareza e precisão. 
Entretanto, deve-se reconhecer que a precisão prescritiva é, por vezes, aspecto preterido dentro do processo legislativo. Um exemplo claro recente é o art. $5^{\circ}$ da Lei $n^{\circ} 13.982$, de 2 de abril de 2020, que instituiu mecanismo de compensação, ao empregador, de custo salarial referente aos primeiros 15 dias pago a empregado licenciado em razão de infecção por Covid-19.

Dentre as várias questões que o preceptivo suscita, discute-se uma, conexa à linguagem eleita, apenas a título ilustrativo: o uso do vocábulo "repasse", em "repasse das contribuições à previdência social”, do qual a empresa pode deduzir determinado montante, gerou a dúvida, tendo em conta que o empregador tem dupla responsabilidade de recolhimento: (i) como sujeito passivo, quanto à contribuição patronal devida; e (ii) como responsável pelo recolhimento da contribuição devida pelo empregado segurado da previdência social.

Logo, de uma perspectiva literal, pode-se dizer que o limite dedutível seria o montante equivalente ao valor retido dos empregados em licença, com máximo definido pelo teto do Regime Geral de Previdência Social (RGPS). Outro sentido seria considerar "repasse" como qualquer transferência desvinculada do binômio retenção x recolhimento, o que permitiria a dedução sobre valores devidos pela empresa como contribuinte, i.e., sobre a devida contribuição previdenciária patronal.

O ponto fulcral é que a Lei nem sempre é clara/precisa, nem sempre tem redação passível de extração de sentido plano, mesmo considerando seus elementos contextuais. Uma dentre as várias razões é o fato de haver tributos cuja complexidade de incidência é tão grande que o legislador não tem compreensão das nuances fundamentais à operação/técnica de tributação; muitas vezes, mesmo especialistas se perdem no intrincado labirinto normativo tributário. A mesma dificuldade é enfrentada pelos magistrados, que sobrecarregados, certamente buscam métodos simplificadores para o exercício do seu mister.

Essa exemplificação da realidade das deficiências qualitativas legísticas se presta a introduzir a utilidade da investigação do espaço criativo do juiz frente à lei obscura ou ambígua. Para tanto, toma-se como referência o modelo da "hermenêutica das escolhas" (GICO JR, 2018, p. 66). Segundo esse desenho, quando a fonte de Direito (lei ou contrato) é obscura, i.e., admite múltiplas leituras, caberá ao juiz eleger a leitura cuja aplicação considera conveniente, e extrair daí a regra jurídica aplicável, descartando-se as demais. Nesse exercício, o dever de eficiência alocativa dita ao juiz que busque, com a escolha interpretativa, que esta se aproxime o quanto possível das preferências sociais. 
Portanto, três situações resumem o quadro em que se dá o exercício adjudicatório: (i) a lei ou o contrato é claro, logo basta efetivar a subsunção ao caso; (ii) há lacuna, e ao julgador cabe se socorrer no escalonamento integrativo, e, ao final, ao extrair a regra e aplicá-la; (iii) a fonte de Direito é obscura, e cabe ao juiz a escolha do sentido adequado e consequente exclusão dos demais.

Sabe-se que a instituição de benefícios é a criação de exceções dentro da regra de tributação, que reduz ou elimina, direta ou indiretamente, dos ônus tributários relativos a obrigações principais e acessórias. Ao analisar o art. 111 do CTN, é notório que ali se disciplina hipóteses de "exceção", logo invoca interpretação literal, e isso em consagração a um postulado que emana efeitos lógicos sobre qualquer ramo jurídico: o que é regra se presume; o que é exceção deve estar expresso em lei (SABBAG, 2010, p. 642). Em regra, é tratamento de adesão facultativa pelo contribuinte, mas peremptoriamente oponível ao ente tributante, quando decorrente de lei válida, vigente e eficaz.

Assim, a menos que a própria lei que institui determine obrigatoriedade (caso de exceção da exceção, possivelmente apenas uma comodidade à administração tributária, ou necessidade que se coloca em face de eventual distorção da técnica de tributação em face de peculiaridades de mercado), a leitura mais acertada é de que se faculta ao contribuinte, potencial beneficiário de regime tributário, fazer opção pelo tal, respeitadas as limitações de oportunidade de adesão, caso existentes.

Juntando a ideia de que o judiciário legisla ao fato de a norma concessiva de benefício exacional ser norma de aplicação alternativa (e facultativa) (ALVES, 2016, p. 11-12) à norma instituidora de tributo, cuja natureza é compulsória, parece ilógico que esta apresente lacuna, pois a indefinição presente na norma isentiva sequer demanda integração, pois pela lógica interpretativa que confronta a exceção e a regra, os limites da exceção são estritos, logo tudo o que não se assinalou em exceção resta sujeito à regra. Assim, se parece que há lacuna, na verdade não há, pois esta é preenchida pela norma ordinária de incidência. Tudo que não for regulado pela norma alternativa não faz parte dessa possibilidade. Assim, haverá lacuna a ser preenchida apenas se esta existir na norma de incidência. Logo, não há espaço para a integração; portanto, não é logicamente possível a ampliação de benefício tributário por meio da analogia.

Por fim, no espaço de exercício da "hermenêutica das escolhas", mesmo em face da diretiva de que a interpretação deve ser literal no CTN (art. 111), restará um problema, pois se há ambiguidade, há mais de uma leitura literal possível (como discutido no exemplo acima). Nesse caso, contudo, o raciocínio de que a criação de norma exoneradora 
é a criação de uma exceção, e a exceção se interpreta de forma restritiva, inclusive quanto à amplitude de efeitos, o corolário necessário é a necessidade de que a versão da norma menos danosa ao ente que cria a concessão seja a eleita. Desse modo, se há dúvida quanto à abrangência dos sujeitos exonerados, ou sobre a apuração do quantum, deve-se trazer para a equação a indisponibilidade do patrimônio público. Logo, entre várias regras possíveis, a mais eficiente é a que melhor preserva o patrimônio público, uma vez que sua disponibilidade também é estritamente vinculada.

Assim, pode-se afirmar que a lei não lega ao julgador qualquer espaço inventivo. Vinculao, seja pelo dever de eficiência - que redunda em adesão à legalidade -, seja informando que não lhe cabe criar benefício fiscal em qualquer situação, ante seus deveres de leitura restritiva e de pautar-se pela impossibilidade de disposição de numerário que integra o patrimônio público.

\section{CONSIDERAÇÕES FINAIS}

Para que o serviço público adjudicatório possa atender à demanda por justiça, seus agentes promotores têm o dever de eficiência ao prover a tutela jurisdicional. Tal eficiência deve se dar tanto em dimensão produtiva, que ocorre quando há esforços para incremento de produtividade ou economicidade, mas também em adequação alocativa, que se dá com a aderência da decisão que solve o caso à lei, reforçando-lhe o valor informacional e seu papel uniformizador, o que redunda em promoção da segurança jurídica. A decisão ampliativa, mesmo quando moralmente apreciada, transborda a lei; portanto, tende a ser alocativamente ineficiente. Para cada novo free rider, maior o peso a ser redistribuído entre os pagantes.

A instituição e a majoração de benefício são temas vinculados à reserva legal, e repletos de condições oponíveis ao legislador. Mesmo que se reconheça legitimidade à atividade legislativa positiva desempenhada pelo Poder Judiciário, sabe-se que o ideal juridicamente é que esta seja limitada aos casos em que o Poder Legislativo delega tal poder criativo, o que se dá nos casos de lacuna ou obscuridade da lei. E isso não pode se dar de forma irrestrita, mas condicionada, inclusive à ponderação de consequências.

A lei que institui benefício fiscal cria exceção dentro da norma tributária de incidência. Logo, pelos cânones clássicos de interpretação, tem limites estritos: tudo o que aquela não regular, restará submetido a esta. Portanto, às lacunas da exceção aplica-se o regramento trivial. Logo, não há como falar em lacuna da lei exoneradora que enseje 
aplicação de métodos integrativos, pois só existirá caso presente na lei que institui o tributo. Por exemplo, se a lei condiciona a definição minudente do objeto a regulamento, não há lacuna integrativa, mas anomia complementar, caso em que a lei será plenamente aplicável apenas após a edição da norma complementar.

A literalidade é a diretriz hermenêutica legalmente instituída para aplicação à lei instituidora de benefício físcal. Razão por que esta deve ser lida dentro do quadro semântico plausível. Se dessa leitura verifica-se ambiguidade e estampam-se várias regras possíveis, o parâmetro material da indisponibilidade do patrimônio público deve nortear a escolha da regra aplicável. Dessa forma, vê-se que tanto nos casos de aparente lacuna, quanto nos de ambiguidade da norma exoneradora, não há espaço para a criação/ampliação de benefícios, seja quanto aos beneficiários, ao quantum, à delimitação fática, espacial ou temporal.

\section{REFERÊNCIAS}

ALVES, Maíza Costa de Almeida. Normas jurídicas concessivas de incentivos fiscais e as facultatividades no Direito tributário brasileiro. 2016. 151 f. Dissertação (Mestrado em Direito) - Pontifícia Universidade Católica de São Paulo, São Paulo, 2016. Disponível em: https://tede2.pucsp.br/handle/handle/7014. Acesso em 22 ago. 2021.

ARRUDA, Gerardo Clésio Maia. A legitimidade do Estado diante das mudanças econômicas e políticas estruturais contemporâneas. Revista da Faculdade de Direito da UFG, n. 43, p. 1-18, 2019. Disponível em: https://www.revistas.ufg.br/revfd/article/view/58533/33659. Acesso em: 20 ago. 2021.

ARRUÑADA, Benito; ANDONOVA, Veneta. Instituições de mercado e competência do Judiciário. In: ZYLBERSTAJN, Décio; SZTAJN, Rachel. Direito \& Economia. Rio de Janeiro: Elsevier, 2005.

BALEEIRO, Aliomar; DERZI, Misabel. Direito tributário brasileiro: CTN comentado. 14. ed. Rio de Janeiro: Forense, 2018. Versão e-book.

BARROSO, Luís Roberto. Judicialização, ativismo judicial e legitimidade democrática. 2009. Disponível em:

https://www.direitofranca.br/direitonovo/FKCEimagens/file/ArtigoBarroso_para_Seleca o.pdf. Acesso em: 21 jul. 2021.

BRASIL. Constituição (1988). Constituição da República Federativa do Brasil. Brasília, DF: Senado, 1988. Disponível em:

http://www.planalto.gov.br/ccivil_03/constituicao/constituicao.htm. Acesso em: 15 ago. 2021. 
BRASIL. Código Tributário Nacional: Lei no 5.172, de 25 de outubro de 1966. Dispõe sobre o Sistema Tributário Nacional e institui normas gerais de Direito tributário aplicáveis à União, Estados e Municípios. Brasília, 1966. Disponível em: http://www.planalto.gov.br/ccivil_03/leis/L5172.htm. Acesso em: 15 set. 2021.

BRASIL. Lei n ${ }^{\circ}$ 8.989, de 24 de fevereiro de 1995. Dispõe sobre a Isenção do Imposto sobre Produtos Industrializados - IPI, na aquisição de automóveis para utilização no transporte autônomo de passageiros, bem como por pessoas portadoras de deficiência física, e dá outras providências. Brasília, 1995. Disponível em: http://www.planalto.gov.br/ccivil_03/leis/18989.htm. Acesso em 20 ago. 2021.

BRASIL, Decreto no 350, de 21 de novembro de 1991. Promulga o Tratado para a Constituição de um Mercado Comum entre a República Argentina, a República Federativa do Brasil, a República do Paraguai e a República Oriental do Uruguai (TRATADO MERCOSUL). Disponível em:

http://www.planalto.gov.br/ccivil_03/decreto/1990-1994/d0350.htm. Acesso em 20 ago. 2021.

BRASIL. Código de Processo Civil Nacional: Lei no 13.105, de 16 de março de 2015. Brasília, 2015. Disponível em: http://www.planalto.gov.br/ccivil_03/_ato20152018/2015/lei/113105.htm. Acesso em: 15 ago. 2021.

BRASIL. Lei de Introdução às normas do Direito Brasileiro. Decreto-Lei no 4.657 , de 4 de setembro de 1942. Disponível em: http://www.planalto.gov.br/ccivil_03/decretolei/del4657compilado.htm. Acesso em: 15 ago. 2021.

BRASIL. Supremo Tribunal Federal. Ação Direta de Inconstitucionalidade por Omissão n 30/DF. Relator Min. Dias Toffoli. Diário de Justiça Eletrônico, Brasília, 6 out. 2020. Disponível em:

http://portal.stf.jus.br/processos/downloadPeca.asp?id=15344602088\&ext=.pdf. Acesso em 12 jun. 2021.

BRASIL. Supremo Tribunal Federal. Enunciado da Súmula Vinculante no 58. Diário de Justiça Eletrônico, Brasília, 7 maio 2020. Disponível em: https://jurisprudencia.stf.jus.br/pages/search/seq-sumula817/false. Acesso em 12 jun. 2021.

BRÄUTIGAM, Deborah. Building Leviathan: Revenue, State Capacity and Governance. IDS Bulletin Vol 33, n. 3, p. 10 - 20, 2002. Disponível em: https://deborahbrautigam.files.wordpress.com/2013/04/2002-building-leviathan.pdf. Acesso em 15 ago. 2021.

COOTER, Robert D.; ULEN, Thomas S. Law \& Economics. 6. ed. Boston: AddisonWesley, 2011.

GICO JR, Ivo Teixeira. Hermenêutica das escolhas e a função legislativa do Judiciário. Revista de Direito Empresarial. Belo Horizonte, ano 15, n. 2, p. 55-84, maio/ago. 2018. Disponível em: 
https://www.researchgate.net/publication/327646609_Hermeneutica_das_Escolhas_e_a _Funcao_Legislativa_do_Judiciario_Choice_Hermeneutics_and_the_Judiciary_Law-

Making_Function. Acesso em: 10 ago. 2021.

GRAU, Eros Roberto. Ensaio e discurso sobre a interpretação/aplicação do Direito. 4. ed. Malheiros Editores, São Paulo: 2006.

HICKS, John Richard. The foundations of welfare Economics. The Economic Journal, Vol. 49, No. 196 (Dec., 1939), p. 696-712. Disponível em: https://www.jstor.org/stable/2225023. Acesso em: 20 jun. 2021.

KALDOR, Nicholas. Welfare propositions of Economics and interpersonal comparisons of Utility. The Economic Journal, Vol. 49, No. 195 (Sep., 1939), p. 549-552.

Disponível em: https://www.jstor.org/stable/2224835. Acesso em: 20 jun. 2021.

KAPLOW, Louis. Taxation. In: POLINSKY, A. Mitchell; SHAVEL, Steven (Eds.). Handbook of law and economics vol.1. Amsterdã: North Holland, 2007.

MISES, Ludwig Von. Human action: a treatise on economics. Auburn: The Ludwig von Mies Institute, 1998. Versão e-book. Disponível em: https://cdn.mises.org/Human\%20Action_3.pdf. Acesso em: 25 jun 2021.

PAULSEN, Leandro. Curso de Direito tributário completo. 11. ed. São Paulo: Saraiva Educação, 2020. Versão e-book.

POSNER, Richard A. “The Economic Approach to Law”. Texas Law Review, v. 53, n. 4, p. 757-781, 1975. Disponível em:

https://chicagounbound.uchicago.edu/cgi/viewcontent.cgi?article=2881\&context=journa 1_articles. Acesso em: 18 jul. 2021.

SABBAG, Eduardo. Manual de Direito tributário. 2. ed. São Paulo: Saraiva, 2010. 